\title{
Review Article \\ Glycyrrhizic Acid in the Treatment of Liver Diseases: Literature Review
}

\author{
Jian-yuan Li, ${ }^{1,2}$ Hong-yan Cao, ${ }^{1,2}$ Ping Liu, ${ }^{1,2}$ Gen-hong Cheng, ${ }^{3}$ and Ming-yu Sun ${ }^{1,2,3}$ \\ ${ }^{1}$ Key Laboratory of Liver and Kidney Diseases, Institute of Liver Diseases, Shuguang Hospital Affiliated to \\ Shanghai University of Traditional Chinese Medicine, 528 Zhangheng Road, Pudong New District, Shanghai 201203, China \\ ${ }^{2}$ Shanghai University of Traditional Chinese Medicine, Shanghai 201203, China \\ ${ }^{3}$ Department of Microbiology, Immunology \& Molecular Genetics, David Geffen School of Medicine, \\ University of California, Los Angeles, CA 90095, USA
}

Correspondence should be addressed to Ming-yu Sun; mysun248@hotmail.com

Received 28 February 2014; Revised 11 April 2014; Accepted 11 April 2014; Published 13 May 2014

Academic Editor: Kota V. Ramana

Copyright (C) 2014 Jian-yuan Li et al. This is an open access article distributed under the Creative Commons Attribution License, which permits unrestricted use, distribution, and reproduction in any medium, provided the original work is properly cited.

\begin{abstract}
Glycyrrhizic acid (GA) is a triterpene glycoside found in the roots of licorice plants (Glycyrrhiza glabra). GA is the most important active ingredient in the licorice root, and possesses a wide range of pharmacological and biological activities. GA coupled with glycyrrhetinic acid and 18-beta-glycyrrhetic acid was developed in China or Japan as an anti-inflammatory, antiviral, and antiallergic drug for liver disease. This review summarizes the current biological activities of GA and its medical applications in liver diseases. The pharmacological actions of GA include inhibition of hepatic apoptosis and necrosis; anti-inflammatory and immune regulatory actions; antiviral effects; and antitumor effects. This paper will be a useful reference for physicians and biologists researching GA and will open the door to novel agents in drug discovery and development from Chinese herbs. With additional research, GA may be more widely used in the treatment of liver diseases or other conditions.
\end{abstract}

\section{Introduction}

The application of natural compounds in the treatment of refractory diseases is a new trend in modern clinical medicine. Because of their satisfactory efficacy in clinic and low toxicity, more natural products are being used as alternative treatments for many diseases. Many hepatoprotective monomers are derived from natural herbs, especially those from China. Glycyrrhizic acid (GA) is an example of one of these hepatoprotective compounds.

The traditional Chinese medicine Gancao (licorice root) is the dried roots of Glycyrrhiza uralensis Fisch (licorice), G. inflata Bat., or G. glabra L. Gancao which was first described in the Chinese book "Shen Nong Ben Cao Jing" in 200 A.D. as an antidote to toxic substances, ache, and other diseases. Gancao can complement other drugs to reduce toxicity and increase efficacy. The traditional use of Gancao involves a decoction of dried plant roots and stems. Some of the possible therapeutic properties of Gancao include antiarthritic [1], antiallergic [2], antiviral [3], antihepatotoxic [4], anticholinergic [5], antiestrogenic [6], anti-inflammatory [6], antileukemogenic [7], and anticarcinogenic effects [8]. It is commonly used for the treatment of acute and chronic liver injury, viral hepatitis, hepatic steatosis, liver fibrosis, hepatoma, viral myocarditis [9], and other diseases like psoriasis [10] or prostate cancer [11].

The known chemical components of Gancao include saponins (mainly glycyrrhizin (GA), 3.63-13.06\%), flavonoids $(1.5 \%)$, coumarin, alkaloids, polysaccharides, sitosterol, and amino acids [12]. GA (Figure 1) and glycyrrhetinic acid (Figure 2) are well-characterized components of Gancao. GA has been developed as a hepatoprotective drug in China and Japan. GA can generate glycyrrhetinic acid through metabolic processes in the human body. Therefore, the pharmacological effects of GA are essentially the same as glycyrrhetinic acid [13]. GA, also called glycyrrhizin, is a triterpene glycoside from licorice root (Glycyrrhiza glabra) and consists of one molecule of $18 \beta$-glycyrrhetinic acid and two 


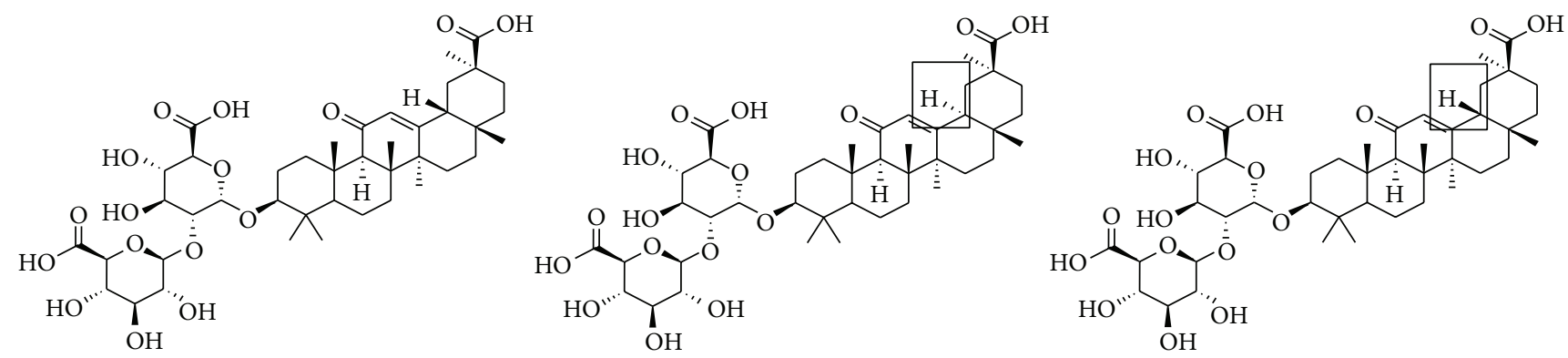

FIgURE 1: Chemical structure of glycyrrhizin (GA) and its derivatives.

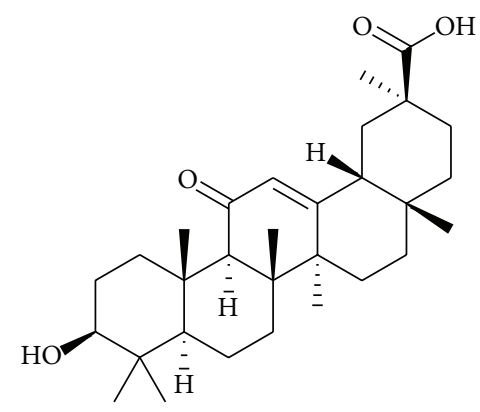

Glycyrrhetinic acid $\mathrm{C}_{30} \mathrm{H}_{46} \mathrm{O}_{4}$

FIGURE 2: Chemical structure of glycyrrhetinic acid.

molecules of glucuronic acid (18 $\beta$-glycyrrhetinic acid-3-O- $\beta$ D-glucuronopyranosyl-(1 $\rightarrow 2$ )-beta-D-glucuronide) $[14,15]$. Glycyrrhizin is considered to be the major active component of Gancao as demonstrated by studies with experimental animal models [16] and clinical studies [17]. GA has been used clinically for more than 20 years in patients with chronic hepatitis in China and Japan [18] and shows a satisfactory therapeutic effect in many other diseases. GA is also widely used as a sweetening and flavoring agent in food.

GA is a main substance of licorice, which is one of the most important substances utilized as traditional medicine for almost 2000 years. Moreover, GA was reported to have antiallergic, antiviral, and anti-inflammatory activities. GA was also found to suppress the rise in fasting blood glucose and insulin levels and improve glucose tolerance. Additionally, GA may act as an antidiabetic substance without inducing side effects, although the mechanism is unclear [19].

GA can form two epimers: $\alpha$-GA and $\beta$-GA (Figure 3). $\alpha$-GA is derived from $\beta$-GA by isomerization, and the $\alpha$ and $\beta$-forms differ only in their $\mathrm{C}_{18}-\mathrm{H}-$, trans-, and cisconfiguration, respectively. Some scholars examined their distribution characteristics in rat tissue and found that the concentrations of $\alpha$-GA in the liver and duodenum were significantly higher than those of $\beta$-GA after i.v. administration. However, the concentrations of $\alpha$-GA in the other tissues were lower than or similar to those of $\beta$-GA and declined rapidly. This indicates that the protective and antiinflammatory effects of $\alpha$-GA on the liver may be better than those of $\beta$-GA [20].

Several clinical studies reported that GA was efficacious in the treatment of various types of inflammation (mainly in liver [21-30] (Table 1), but also in lung, kidney, intestine, and spinal cord [31]). The most common use of GA is in the treatment of liver disease [32]. GA can reduce steatosis and necrosis of liver cells significantly [33] to inhibit the inter-interstitial inflammation and liver fibrosis and promote cell regeneration. GA has few side effects and is therefore considered to be a drug worth attention and promotion for liver disease.

\section{Mechanisms of GA Effects}

2.1. Inhibition of Hepatic Apoptosis and Necrosis. Tumor necrosis factor-alpha (TNF- $\alpha$ ) is an important cytokine, which is a key mediator of hepatic apoptosis and necrosis in LPS/D-GaAlN-induced liver failure [34]. Plasma TNF- $\alpha$ level is also elevated in patients with chronic hepatitis caused by hepatitis B viral [35] and acute alcoholic hepatitis [36]. Therefore, TNF- $\alpha$ plays a key role in the pathogenesis of not only endotoxin-induced experimental liver injury but also many human liver diseases. Caspase-3 activation is an indicator of almost all apoptosis systems [37]. GA has anti-inflammatory and antiapoptotic effects via suppression of TNF- $\alpha$ and caspase- 3 and these are used to explain the hepatoprotective effect of GA (Table 2) [38]. GA also significantly inhibits the release of cytochrome $\mathrm{C}$ from mitochondria into the cytoplasm. The anti-inflammatory activity of GA may rely on the inhibition of release of TNF- $\alpha$, myeloperoxidase activity, and translocation of nuclear factor- $\kappa \mathrm{B}$ (NF- $\kappa \mathrm{B}$ ) into the nuclei. GA also upregulated the expression of proliferating cell nuclear antigen, implying that it might be able to promote regeneration of liver injury [39]. Activated Kupffer cells are involved in ischemia-reperfusion- (I/R-) induced liver injury and high-mobility group box 1 (HMGB1) production. GA was shown to inhibit HMGB1 production by Kupffer cells and prevented I/R-induced liver injury [40]. GA could also alleviate I/R-induced [41] and spinal cord [42] injury via this 




18-Alpha-glycyrrhetinic acid $\mathrm{C}_{30} \mathrm{H}_{46} \mathrm{O}_{4}$



18-Beta-glycyrrhetinic acid $\mathrm{C}_{30} \mathrm{H}_{46} \mathrm{O}_{4}$

FIGURE 3: Chemical structure of $18 \alpha$-glycyrrhetinic acid and $18 \beta$-glycyrrhetinic acid.

mechanism. In addition, GA conjugates free radicals, which might explain the protective action of GA [43]. For example, GA can be an effective chemopreventive agent against lead acetate mediated hepatic oxidative stress in rats because it binds lead [44]. In concanavalin A- (ConA-) induced mouse model, GA alleviated ConA-induced inflammation and fibrosis progression in livers via inhibition of CD4+ T cell proliferation in response to ConA via the Jun $\mathrm{N}$-terminal kinase (JNK), extracellular signal-regulated kinase (ERK), and phosphoinositide 3-kinase (PI3K)/AKT pathways [45].

2.2. Anti-Inflammation and Immunity Regulation. GA suppressed interleukin-6 (IL-6) and TNF- $\alpha$ production induced by the lipid A moiety of lipopolysaccharides (LPS) in RAW264.7 cells. It inhibited lipid A-induced NF- $\kappa \mathrm{B}$ activation in $\mathrm{Ba} / \mathrm{F} 3$ cells expressing toll-like receptor 4 (TLR4)/myeloid differentiation protein-2 (MD-2), cluster of differentiation 14 (CD14), and bone marrow-derived macrophages (BMMs). GA also inhibited activation of mitogen-activated protein kinase (MAPKs), including JNK, p38 protein, and ERK in BMMs. In addition, GA inhibited NF- $\kappa$ B activation and IL- 6 production induced by paclitaxel, a nonbacterial TLR4 ligand. It attenuated the formation of the LPS-TLR4/MD-2 complexes, resulting in inhibition of homodimerization of TLR4. Therefore, GA modulated the TLR4/MD-2 complex at the receptor level, leading to suppression of LPS-induced activation of signaling cascades and cytokine production. This indicates that GA can attenuate inflammatory responses and modulate innate immune responses [46]. Moreover, GA can prevent the activation of signal transducers and activators of transcription-3 (STAT-3), reduce the upregulation of intercellular cell adhesion molecule (ICAM-1) and Pselectin expression, reduce formation of poly(adenosine diphosphate-ribose) (PAR) and nitrotyrosine, and reduce polymorphonuclear neutrophil (PMN) infiltration. Some observations suggest that broad anti-inflammatory activity of GA is mediated by interaction with the lipid bilayer, thereby attenuating receptor mediated signaling [47]. GA inhibited the lytic pathway of the complement system and may prevent tissue injury caused by the membrane attack complex.
Therefore, GA could be a potent agent for suppressing complement-dependent tissue injury in autoimmune and inflammatory diseases [48]. GA can suppress systemic inflammatory response syndrome (SIRS) associated anti-inflammatory response manifestation via inhibition of $\mathrm{CC}$ chemokine ligand 2 (CCL2) production by PMN. It may also have the potential to inhibit anti-inflammatory responseassociated opportunistic infections in critically ill patients with severe SIRS [49]. There are also other studies that indicated the same anti-inflammatory mechanisms of GA [50].

2.3. Antiviral Effects. The antiviral mechanisms of GA mainly include the inhibition of viral replication and immunity regulation. GA affects cellular signaling pathways such as protein kinase $\mathrm{C}$ and casein kinase II and transcription factors such as activator protein 1 and NF- $\kappa$ B. Furthermore, nitrous oxide (NO) inhibits replication of several viruses like Japanese encephalitis virus 4 (a member of the Flaviviridae family), which can also be inhibited by GA. The powerful anti-inflammatory capabilities of GA make it effective in the treatment of various types of hepatitis like viral hepatitis and nonalcoholic hepatitis. GA was found to inhibit the replication of the SARS-associated virus [51]. In the treatment of HCV (hepatitis C virus) infection, GA can inhibit $\mathrm{HCV}$ full-length viral particles and $\mathrm{HCV}$ core gene expression or function in a dose-dependent manner and have a synergistic effect with interferon [52]. GA is also involved in biliary secretion and excretion. GA can increase hepatic glutathione levels by the inhibition of biliary excretion of glutathione partly through the inhibition of MRP2 [53], an efflux transporter located at the canalicular membrane of a hepatocyte. MRP2 translocates glutathione, LTC4, bilirubin, methotrexate (MTX), glucuronide (e.g., estradiol-17- $\beta$ glucuronide $\left[\mathrm{E}_{2} 17 \mathrm{G}\right]$ ), or sulfate conjugates and other organic anions from a hepatocyte into the bile canaliculus [54-58].

GA can activate certain immune functions, such as IFN production, augmentation of NK cell activity, and modulation of the growth response of lymphocytes via augmentation of IL-2 production [70]. GA can enhance immune function 


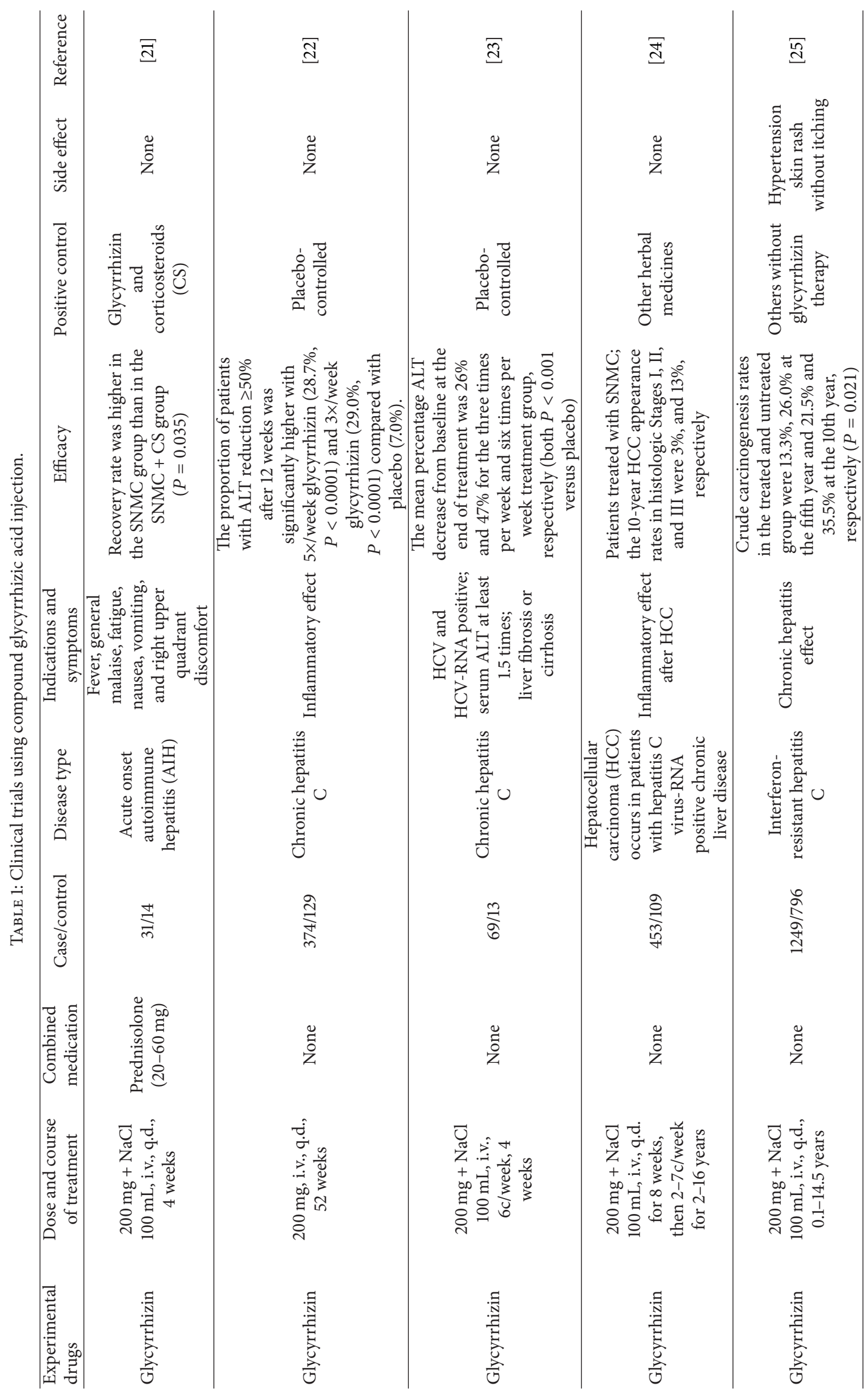




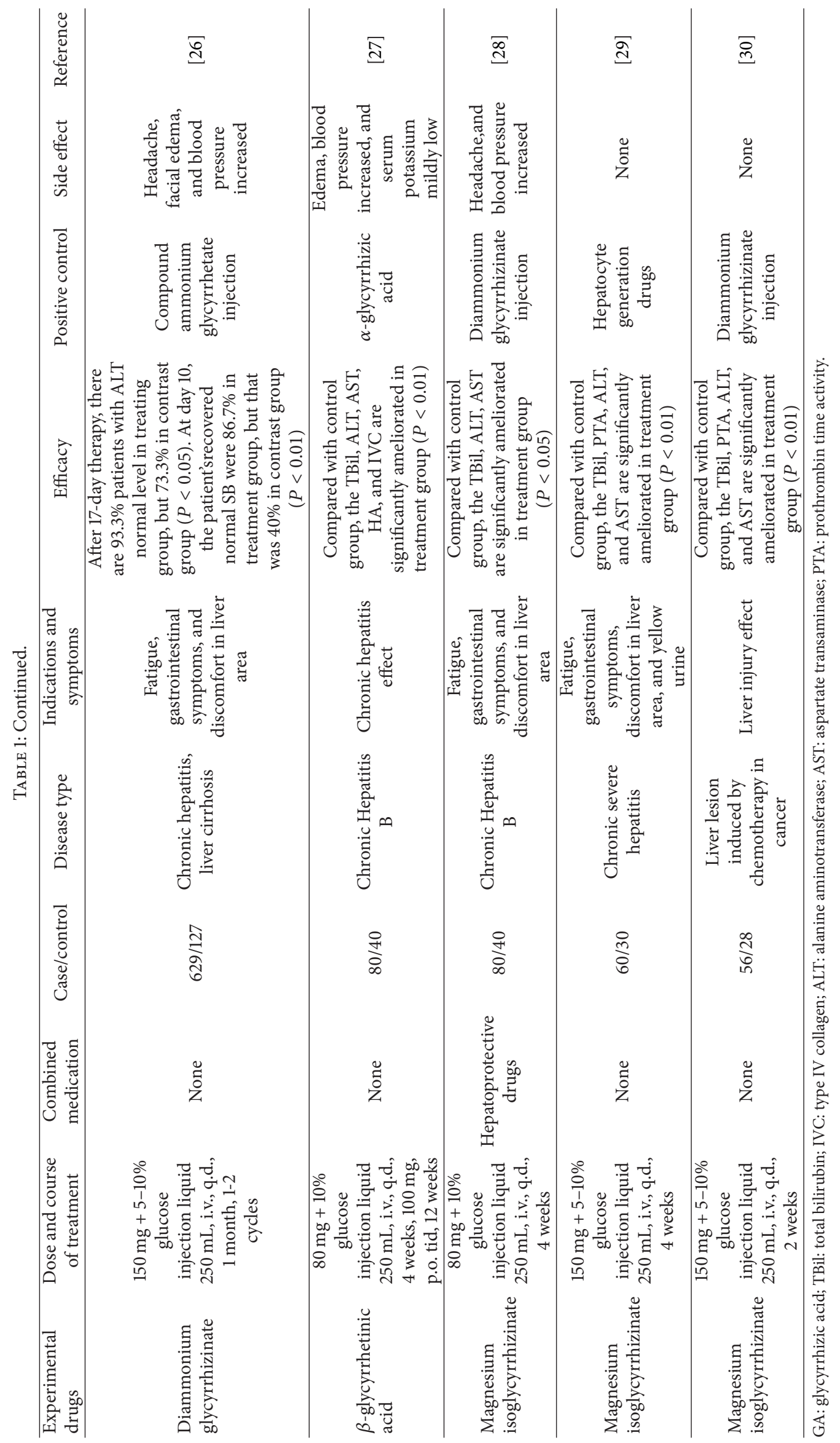




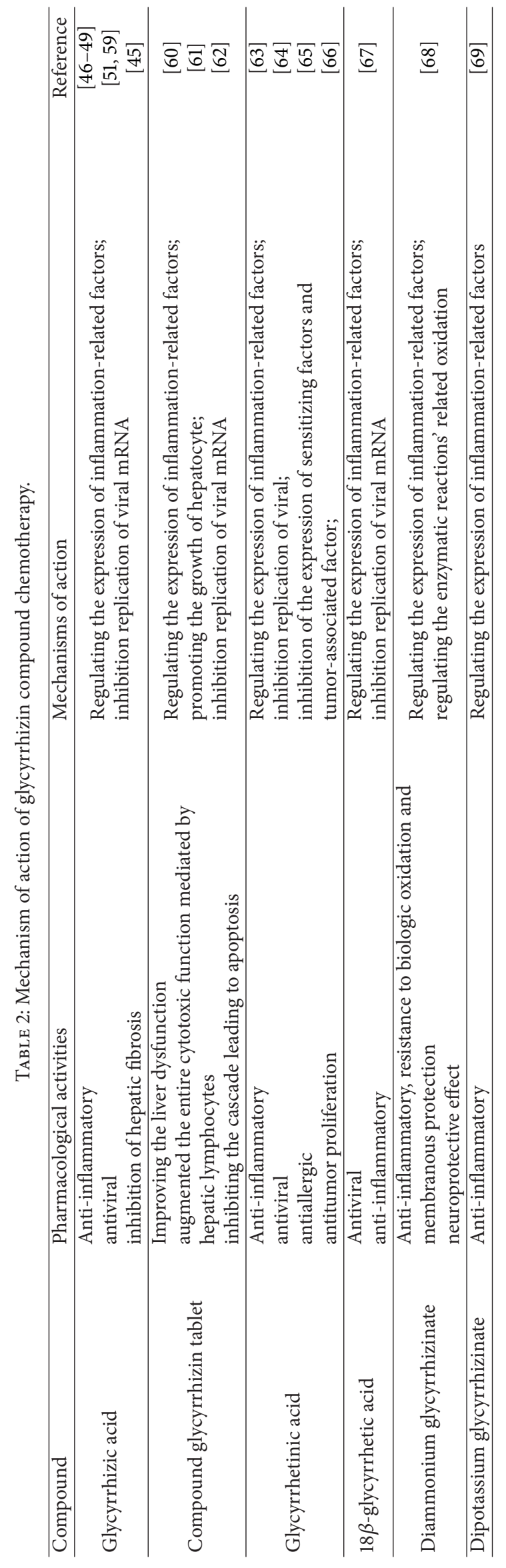


TABLE 3: Patents of glycyrrhizin extracts.

Patent Patent number

Acetylated 18-alpha glycyrrhizic acid and preparation method thereof CN102351937 A

Ammoniated glycyrrhizin modified sweetened beverage products

US2008226787(A1)

Application of beta-glycyrrhizic acid and derivatives thereof for radiation protection

CN102206242 A

Application of glycyrrhetinic acid and glycyrrhizic acid in preparing medicaments for preventing or treating pulmonary fibrosis

CN101919870 B

Application of glycyrrhizic acid and glycyrrhetic acid in preparing medicine for inflammatory enteropathy

CN1846705 A

Application of glycyrrhizic acid in preparation of sunitinib malate cardiotoxicity

CN103285020 A

reduction drug

Application of glycyrrhizic acid on treating dilated cardiomyopathy cardiac remodeling and cardiac dysfunction

CN102247392 A

Application of glycyrrhizic acid, glycyrrhetinic acid, or salt thereof as well as gel composition and preparation method for gel composition

CN102614213 A

Application of glycyrrhizic acid and its breakdown product glycyrrhetinic acid for the manufacture of a medicament for the treatment of inflammatory bowel disease

US2010087385(A1)

Aqueous pharmaceutical solutions with trisubstituted glycyrrhizic acid salts

EP1226831 A1

Aspergillus niger bacterial strain and glycyrrhizic acid used for production thereof

CN101255401 B

Berberine glycyrrhizic acid enantiomer salt and preparation method and usage thereof

CN101747405 A

Biological extraction process of glycyrrhizic acid

CN101067146 B

Carboxymethyl chitosan nanoparticles modified with glycyrrhizic acid, preparation method, and application thereof

CN102357079 A

Chitosan glycyrrhizic acid nanoparticle and its preparing method

CN1586488 A

Composite glycyrrhizic acid amino acid injection and preparation method as well as applications thereof

CN101669962 A

Compositions containing glycyrrhizin

US4678772(A)

Compound for the control of herpes simplex virus using glycyrrhizic acid, lipoic acid, allantoin, and slippery elm

US2011229584(A1)

Compound glycyrrhizin capsule composition

CN103230407 A

Compound glycyrrhizin soluble powder for livestock and preparation method thereof

CN102526082 B

Dispersed compound tablet of glycyrrhizic acid and glycyrrhizinate and its preparing process

CN100386086 C

Enteric-coated formulation of glycyrrhizic acid and its salt and its preparing method

CN1274309 C

Film-coated tablet of glycyrrhizinic acid monopotassium salt and method for preparing the same

CN100341515 C

Glycyrrhizic acid compounds as foamer in chemically derived surfactant-free

US2008274062(A1) dentifrice

Glycyrrhizic acid and its derivative used as RANTES inducer

CN1498623 A

Glycyrrhizic acid antibody and its preparing method and use

CN1293097 C

Glycyrrhizic acid aureola dimer mediated targeted medication body as well as preparation method and purpose of glycyrrhizic acid aureola dimer mediated targeted

CN102716488 A medication body

Glycyrrhizic acid composition

CN101081227 B

Glycyrrhizic acid derivatives having amino acid, its preparation method, and

CN1911954 A

medicinal composition containing them

CN100537593 C

Glycyrrhizic acid double salt and preparation thereof

CN100564391 C 
TABle 3: Continued.

\begin{tabular}{|c|c|}
\hline Patent & Patent number \\
\hline Glycyrrhizic acid organic salt phospholipid ligand and preparation thereof & CN102716463 A \\
\hline Glycyrrhizic acid removal glycyrrhiza flavonoid and medicament composition thereof & CN101747307 A \\
\hline Glycyrrhizic acid sustained-release dropping pills and preparation method thereof & CN101269020 A \\
\hline Glycyrrhizic acid transdermal formulation and preparation technique thereof & CN101433529 A \\
\hline $\begin{array}{l}\text { Glycyrrhizic acid, biogastrone acid or its salt, derivative temperature sensing gel } \\
\text { rubber, preparation method, and application thereof }\end{array}$ & CN101292952 B \\
\hline Glycyrrhizin high-concentration preparation & US2006160754(A1) \\
\hline $\begin{array}{l}\text { Glycyrrhizin or derivatives thereof for treating or preventing severe acute respiratory } \\
\text { syndrome (SARS) }\end{array}$ & US2007099855(A1) \\
\hline Glycyrrhizin preparations for transmucosal absorption & US6890547(B1) \\
\hline Glycyrrhizin-free fractions from licorice root and process for obtaining such fractions & US4163067(A) \\
\hline $\begin{array}{l}\text { Inclusion compound of glycyrrhizic acid or its derivative and alkaloid and its } \\
\text { preparation method }\end{array}$ & CN1301717 C \\
\hline Magnetic resonance imaging contrast medium with glycyrrhizic acid as carrier & CN101002950 B \\
\hline Medicine composition of glycyrrhizic acid or its salt and reduced glutathione & CN1985987 B \\
\hline Medicine composition of glycyrrhizic acid or its salt, ginseng and astragalus root & CN1985873 B \\
\hline $\begin{array}{l}\text { Medicine composition prepared mainly from glycyrrhizic acid or its salt, ginseng and } \\
\text { glossy ganoderma }\end{array}$ & CN1985864 B \\
\hline $\begin{array}{l}\text { Method for determining glycyrrhizic acid content in extract after polysaccharide } \\
\text { extraction of glycyrrhiza by virtue of vanillin-sulfuric acid }\end{array}$ & CN102621089 A \\
\hline Method for extracting and purifying glycyrrhizic acid by ion-exchange fibers & CN102304165 B \\
\hline $\begin{array}{l}\text { Method for measuring paeoniflorin, hesperidin, and glycyrrhizic acid in } \\
\text { stomach-nourishing granules }\end{array}$ & CN103175915 A \\
\hline $\begin{array}{l}\text { Method for producing glycyrrhizin sodium aliphatate or glycyrrhizin potassium } \\
\text { aliphatate }\end{array}$ & CN101830962 B \\
\hline Method for producing glycyrrhizic acid through enzymolysis & CN102219824 B \\
\hline $\begin{array}{l}\text { Method for separating and purifying glycyrrhizic acid extracting solution through } \\
\text { macroporous resin separation }\end{array}$ & CN103242393 A \\
\hline $\begin{array}{l}\text { Method of preparing } 18 \text { alpha type glycyrrhizic acid and its salt using } \\
\text { nonhomogeneous phase reaction }\end{array}$ & CN100522985 C \\
\hline Nanocapsule containing glycyrrhizic acid medicine and its preparing method & CN1319537 C \\
\hline Novel glycyrrhizic acid double salt and preparation and application thereof & CN103242392 A \\
\hline $\begin{array}{l}\text { Pharmaceutical antiviral composition comprising glycyrrhizic acid and at least one } \\
\text { protein endowed with antiviral activity }\end{array}$ & US6329339(B1) \\
\hline $\begin{array}{l}\text { Pharmaceutical antiviral composition, comprising glycyrrhizic acid and at least one } \\
\text { protein endowed with antiviral activity }\end{array}$ & CN1114447 C \\
\hline Pharmaceutical applications of glycyrrhizic acid or salt and derivative thereof & CN102552280 A \\
\hline Potassium-magnesium-calcium glycyrrhizin & US4176228(A) \\
\hline Potentiation of chocolate flavor with ammoniated glycyrrhizin & US3356505(A) \\
\hline $\begin{array}{l}\text { Powder injection of compound glycyrrhizic acid glycosides and preparation method } \\
\text { thereof }\end{array}$ & CN101317852 B \\
\hline Preparation method for trans-glycyrrhizic acid & CN102584928 A \\
\hline Preparation method of high-purity glycyrrhizic acid & CN103159809 A \\
\hline Preparation method of glycyrrhizic acid & CN101759757 A \\
\hline Process for extracting purified glycyrrhizic acid from licorice residue & CN1450081 A \\
\hline Process for producing glycyrrhizic acid & CN102617694 A \\
\hline
\end{tabular}


TABLE 3: Continued.

\begin{tabular}{lc}
\hline Patent & Patent number \\
\hline Products sweetened with alpha-glycosyl glycyrrhizin & US4537763(A) \\
Separation and purification process of glycyrrhizic acid & CN102453075 A \\
Separation of glycyrrhizic acid from licorice extract by ultrafiltration & US2011196138(A1) \\
Separation, purification, and concentration device for glycyrrhizic acid extract & CN202909639 U \\
Silver glycyrrhizic acid and its producing process and use thereof & CN1063184C \\
$\begin{array}{l}\text { Slow-released compound preparation of glycyrrhizic acid and glycyrrhizinate and its } \\
\text { preparing process }\end{array}$ & CN1857288 A \\
$\begin{array}{l}\text { Sucrose-ammoniated glycyrrhizin sweetening agent } \\
\text { Supercritical CO2 extraction method for extracting glycyrrhizinic acid from licorice }\end{array}$ & US3282706(A) \\
$\begin{array}{l}\text { Technique for extracting glycyrrhizin using hot reflux method } \\
\text { The application of glycyrrhizic acid and its breakdown product glycyrrhetinic acid for } \\
\text { the manufacture of a medicament for the treatment of inflammatory bowel disease }\end{array}$ & CN1136225 C \\
$\begin{array}{l}\text { The application of glycyrrhizic acid and its breakdown product glycyrrhetinic acid for } \\
\text { the manufacture of a medicament for the treatment of inflammatory bowel disease }\end{array}$ & WO2007073083090 A A \\
Ultrasonic extracting method for changing glycyrrhizic acid leaching phase balance & EP2067476 A1 \\
$\begin{array}{l}\text { Use of glycyrrhetic acid and/or glycyrrhizin for producing cosmetic preparations for } \\
\text { tanning the skin }\end{array}$ & CN101486750 A \\
$\begin{array}{l}\text { Use of glycyrrhetinic acid, glycyrrhizic acid, and related compounds for prevention } \\
\text { and/or treatment of pulmonary fibrosis }\end{array}$ & US2009280074(A1) \\
Use of glycyrrhizin and its derivatives as MCP-1 production inhibitors & US2012053141(A1) \\
Use of glycyrrhizin and its derivatives as RANTES inducers & US2004138171(A1) \\
Use of glycyrrhizin for the treatment of standard therapy-resistant hepatitis C patients & US2004142882(A1) \\
Use of iso-glycyrrhizic acid and salt thereof in treating allergic rhinitis & WO2004056374 A1 \\
Use of one or more of glycyrrhizic acids for reducing the irritating action of & CN101396368 B \\
surfactants in cosmetic compositions & US2011015143(A1) \\
\hline
\end{tabular}

in mice [71]. GA treatment could significantly reduce blood immunoglobulin E (IgE), interleukin-4 (IL-4), interleukin-5 (IL-5), interleukin-6 (IL-6), NO, TNF- $\alpha$ levels, and nitrous oxide synthase (NOS) activity dose-dependently. GA could also enhance blood immunoglobulin A (IgA), immunoglobulin $\mathrm{G}$ (IgG), immunoglobulin M (IgM), interleukin-2 (IL2), and interleukin-12 (IL-12) levels in AR mice. Gr- $1^{+} \mathrm{CD} 11^{+} \mathrm{b}$ cells are responsible for numerous pathological processes such as $\mathrm{T}$ cell dysfunction after severe trauma or major surgery, leading to increased susceptibility to infection [72]. These cells exercise an inhibitory effect on MBD-1 production of EKs mediated via the suppressor molecules CCL-2 and IL10. GA acts as a potent inhibitor of these cells and therefore restores MBD-1 levels. This restoration affects $\mathrm{T}$ cell dysfunction [73]. In thermally injured mice, GA regulates the burnassociated type $2 \mathrm{~T}$ cell responses to recover IL-12 and make it unresponsive, thus restoring the impaired cells [74]. GA acts as a promoter of the late signal transduction of $\mathrm{T}$ lymphocytes for IL-2 production. The balance between augmenting and suppressing effects might be dependent on the level of stimulation and stage of the cell. Therefore, this determines quality and quantity of the immunomodulatory action of GA [75]. In blood and nasal mucosa, GA consumption decreases antioxidant enzyme activity, lipid peroxidation, Glutathione levels, and IL-4 levels and enhances IFN- $\gamma$, thus protecting the nasal mucosa from oxidative injury and improving immunity activity [76].

GA interferes with some viruses, such as H5N1 [77]. The replication and virus-induced proinflammatory gene expression include inhibition of the virus-induced formation of reactive oxygen species and reduced activation of NF$\kappa \mathrm{B}$, JNK, and $\mathrm{p} 38$, which are redox-sensitive signaling events known to be relevant for replication.

2.4. Antitumor Effects. CYP enzymes are mainly found in the liver and bowel wall. They are responsible for the bulk of phase I or oxidative metabolism of xenobiotics including dietary toxins, carcinogens, mutagens, and drugs. Administration of GA was able to significantly induce CYP content, which reduces the incidence of cancer [78]. GA can also protect against aflatoxin-induced oxidative stress. The protective effect is likely from its capacity to inhibit the metabolic activation of hepatotoxin, a critical factor in the pathogenesis of chemical-induced carcinogenicity [79]. O-carboxymethyl chitosan nanoparticles (CMCNP) modified by GA with 
various substitution degrees can efficiently deliver paclitaxel (PTX) to hepatocellular carcinomas (HCC). CMCNP-GA significantly facilitated the increased accumulation of PTX in hepatic tumor tissues and the targeted delivery of PTX to hepatoma carcinoma cells, which resulted in remarkably enhanced in vitro cytotoxicity and in vivo antitumor efficacy [80]. In a diethylnitrosamine-treated experimental animal study, as a chemopreventive agent of HCC, modulation of cell proliferation and apoptosis by GA may be associated with inhibition of HCC. Therefore, GA treatment may inhibit the occurrence of HCC [81].

2.5. Inductive Effect of Liver Enzyme Activity. Some studies showed that GA has an inductive effect on CYP3A activity. Therefore, clinicians should pay attention to other drugs catalyzed by CYP3A, especially those substrates with a narrow therapeutic range such as cyclosporine $A$, to avoid possible clinically significant interactions with GA [82]. Some studies revealed that the area under concentration-time curve and the mean retention time of methotrexate (MTX) were significantly increased by GA, which increases the adverse reactions of MTX [83]. MTX is an antifolate agent, anticancer agent, and immunosuppressant and is commonly used for anticancer chemotherapy [84], rheumatoid arthritis [85], and severe psoriasis [86]. The adverse reactions of MTX include nausea, vomiting, diarrhea, and hepatotoxicity [87, 88]. A case report showed that combined administration of GA and cilostazol caused pseudoaldosteronism [89]. Therefore, the concurrent use of GA with MTX or cilostazol is not recommended. One report shows a case of hypokalemic rhabdomyolysis secondary to chronic GA intoxication [90]. GA ingestion could therefore potentially aggravate hypokalemia in patients with chronic laxative abuse [91], indicating that the use of GA in hypokalemia should be treated with caution.

\section{Other Pharmacological Activities}

GA is effective in combating hyperglycemia and associated pathological complications such as hyperlipidemia, abnormal histoarchitectures of different organs, and oxidative stress including hemoglobin-induced iron-mediated free radical reactions. The effects of GA on diabetes-associated changes are almost comparable with those of glibenclamide, a standard antihyperglycemic drug, suggesting a possible use of the herbal agent as a drug to prevent complications of diabetes mellitus [92]. Furthermore, GA regulates renal function through the regulation of water channels [93], and GA administration ameliorates the renal concentrating ability and structural lesions in renal tissues in rats with early-phase of ischemia-acute renal failure [94]. As a reduction inhibitor, GA reduces the therapeutic loss of methylprednisolone produced from methylprednisolone 21-sulfate sodium in the large intestine, thus improving the therapeutic property of the prodrug against inflammatory bowel disease [95]. GA also offers protection from the damage induced by UVB radiation in humans. Therefore, it could be considered as a promising agent for addition to topical formulations for the prevention of skin cancer [96]. GA significantly alleviates asthma symptoms [97], inhibits lung inflammation [98], and relieves acute lung injury $[35,99]$. It can directly affect cardiac performance and play a role in myocardial and coronary protection in the presence of cardiovascular diseases [100]. GA may prevent brain tissue damage [101], can be a putative therapeutic drug for neurodegenerative diseases associated with cognitive deficits and neuroinflammation such as Alzheimer's disease [102], and could suppress ocular hypertension with potential therapeutic effects in eye disease [103]. GA improves resistance to C. albicans infection by inducing CD4+ T cells, which suppress type 2 cytokine production by Th2 cells [104]. GA inhibits activated macrophage (M2M) generation stimulated with neutrophils. The regulation of neutrophilassociated M2M generation by GA may provide a new therapeutic strategy, which could influence the outcome of certain severe infections in hosts with M2M generation [105].

\section{Drugs That Include GA}

Drugs made with GA have been on the market for many years, and most have important therapeutic uses. Magnesium isoglycyrrhizinate injection (TianQing GanMei, Chia Tai Tainqing, JiangSu, China) is one example of a drug with GA. Magnesium isoglycyrrhizinate is an effective and safe treatment for chronic liver diseases [106] and is capable of slowing down the progress of pulmonary fibrosis [107]. Moreover, diammonium glycyrrhizinate enteric-coated capsules (TianQing GanPing, Chia Tai Tainqing, JiangSu, China) and diammonium glycyrrhizinate injection (GanLiXin, Chia Tai Tainqing, JiangSu, China) are used for acute and chronic hepatitis associated with elevated alanine aminotransferase. Stronger neo-minophagen C (SNMC, Minophagen Pharmaceutical, Tokyo, Japan) is often used in the treatment of chronic liver disease and can improve liver dysfunction [60]. SNMC is a compound GA tablet that includes GA (2 mg) with glycine acid $(20 \mathrm{mg})$ and L-cysteine hydrochloride (1 mg). SNMC has anti-inflammatory, antiallergic, steroidlike, anticomplementary, and immunoregulatory effects.

\section{GA Combined with Matrine}

GA combined with matrine (Mat) can improve CCL4induced liver fibrosis effectively. This is evidenced by lower levels of collagen, hyaluronic acid (HA), and laminin (LN), less hepatic stellate cells (HSC) proliferation, collagen I, and HA levels secreted by HSC in vitro with combined therapy compared with GA or Mat alone. GA combination with Mat could protect liver cells and inhibit hepatic fibrosis and may therefore be a safe and effective strategy for improving hepatic fibrosis [108]. In an animal model, GA combined with Mat reduced the mortality of acetaminophen overdosed mice, attenuated acetaminophen-induced hepatotoxicity, and reduced the number and area of $\mathrm{y}$-GT positive foci, thus protecting liver function and preventing HCC from occurring [109]. Additionally, the combination of GA and cyclosporine was an effective treatment for nonsevere aplastic anemia [110]. 


\section{Common Derivatives of Glycyrrhizin}

Glycyrrhetinic acid (3 $\beta$-hydroxy-11-oxo-oleana-12-en-28-oic acid), the aglycone of GA, stimulates glucose-induced insulin secretion in isolated pancreatic islets. Glycyrrhetinic acid treatment enhances plasma insulin levels and reduces the levels of gluconeogenic enzymes in liver. It is a pentacyclic triterpene acid with numerous biological activities, including anti-inflammatory [63], antiviral [64], antiallergic [65], and antitumor proliferative effects [66].

Glycyrrhetinic acid restrains the proliferation of skin tumors in mice and human breast cancer cells (MCF7) and induces apoptosis of cancer cells. The mechanism of apoptosis might be via increased free $\mathrm{Ca}^{2+}$ level in the cells [111]. Mizushina et al. [112] demonstrated that glycyrrhetinic acid potently inhibited the activity of mammalian polymerases, including pol $\lambda$. Glycyrrhetinic acid also reduced TNF- $\alpha$ production and NF- $\kappa \mathrm{B}$ activation and suppressed mouse ear inflammation stimulated by tissue plasminogen activator. Therefore, glycyrrhetinic acid could be an anti-inflammatory agent based on pol $\lambda$ inhibition.

Another licorice acid derivative is $18 \beta$-glycyrrhetic acid. The triterpene structure of the HMGB1-binding compound is capable of binding to HMGB1 and altering its proinflammatory properties, inhibiting HMGB1-dependent cyclooxygenase (COX) 2 induction [113]. 18 $\beta$-glycyrrhetic acid has significant antiviral activity against rotavirus replication in vitro, and studies to determine whether $18 \beta$-glycyrrhetic acid attenuates rotavirus replication in vivo are underway, although the exact mechanism is unclear. However, some reports show that $18 \beta$-glycyrrhetic acid inhibits NF- $\kappa \mathrm{B}$ activation, which has been interpreted as $18 \beta$-glycyrrhetic acidmediated regulation of the inflammatory response [114]. 18 $\beta$ glycyrrhetinic acid can also inhibit the activity of tyrosine and prevent melanin growth and whitening. Some reports show that $18 \beta$-glycyrrhetinic acid is likely responsible for amelioration of dysfunction of glutamate transport in astrocytes, and the inhibition of protein kinase $\mathrm{C}$ activity might be related to its pharmacological efficacy [67].

\section{Conclusions and Future Perspectives}

This review summarized the efficacy of GA in liver disease from clinical trials and its mechanisms of action in vitro and in vivo. Studies indicate that GA could modulate various molecular pathways in liver disease. There are numerous patents for drugs including GA (Table 3). Studies described here highlight the use of GA as a novel chemopreventive agent for liver injury. It is expected that future studies with GA will help to define various molecular mechanisms and targets for inflammation and steatosis. At present, the number of multicenter, large sample, randomized, doubleblind, controlled chemoprevention clinical trials with GA is very limited. Extensive clinical research is warranted to evaluate the safety and chemopreventive efficacy of GA alone or in combination with chemotherapy agents.

\section{Conflict of Interests}

The authors declare that there is no conflict of interests regarding the publication of this paper.

\section{Acknowledgments}

This work is supported by the National Natural Science Foundation (no. 81273729), Major Project of Shanghai Municipal S\&T Commission (no. 11DZ1971702), Shanghai RisingStar Program (08QA14062), Wang Bao-En Hepatic Fibrosis Research fund (20100048), and E-institute of Shanghai Municipal Education Commission (Project no. E03008). Innovative Research Team in Universities, Shanghai Municipal Education Commission, Shanghai Key Laboratory of Traditional Chinese Clinical Medicine, and Key Disciplines of Liver and Gall Bladder Diseases of State Administration of Traditional Chinese Medicine of the People's Republic of China.

\section{References}

[1] M. L. Gujral, K. Sareen, D. P. Phukan, and M. K. Amma, "Antiarthritic activity of glycyrrhizin in adrenalectomised rats," Indian Journal of Medical Sciences, vol. 15, pp. 625-629, 1961.

[2] A. Kumagai, M. Nanaboshi, Y. Asanuma, T. Yagura, and K. Nishino, "Effects of glycyrrhizin on thymolytic and immunosuppressive action of cortisone," Endocrinologia Japonica, vol. 14, no. 1, pp. 39-42, 1967.

[3] R. Pompei, O. Flore, M. A. Marccialis, A. Pani, and B. Loddo, "Glycyrrhizic acid inhibits virus growth and inactivates virus particles," Nature, vol. 281, no. 5733, pp. 689-690, 1979.

[4] Y. Kiso, M. Tohkin, H. Hikino, T. Sakamoto, and T. Namba, "Mechanism of antihepatotoxic activity of glycyrrhizin. I: effect on free radical generation and lipid peroxidation," Planta Medica, vol. 50, no. 4, pp. 298-302, 1984.

[5] A. L. Leroy, Contribution a' l'étude des propriétés pharmacodynamiques dex extraits de reglisse (Glycyrrhiza glabra kgumineuse) [Thesis], University of Paris, Faculty of Medicine, vol. 592, pp. 1-49, 1959.

[6] C. Nieman, "Pharmacological properties of liquorice," Chemist and Druggist, vol. 177, pp. 741-745, 1962.

[7] W. Logemann, F. Lauria, G. Cudkowicz, and J. Franceschini, "Antileukæmic activity of glycyrrhetinic acid," Nature, vol. 187, no. 4737 , pp. $607-608,1960$.

[8] J. C. Mirsalis, C. M. Hamilton, J. E. Schindler, C. E. Green, and J. E. Dabbs, "Effects of soya bean flakes and liquorice root extract on enzyme induction and toxicity in B6C3F1 mice," Food and Chemical Toxicology, vol. 31, no. 5, pp. 343-350, 1993.

[9] H.-C. Zhang, Y.-X. Song, and Z.-C. Zhang, "Glycyrrhizin administration ameliorates coxsackievirus B3-induced myocarditis in mice," The American Journal of the Medical Sciences, vol. 344, no. 3, pp. 206-210, 2012.

[10] S. Q. Deng, B. H. May, A. L. Zhang, C. J. Lu, and C. C. L. Xue, "Topical herbal medicine combined with pharmacotherapy for psoriasis: a systematic review and meta-analysis," Archives of Dermatological Research, vol. 305, no. 3, pp. 179-189, 2013.

[11] S. Thiugnanam, L. Xu, K. Ramaswamy, and M. Gnanasekar, "Glycyrrhizin induces apoptosis in prostate cancer cell lines DU-145 and LNCaP," Oncology Reports, vol. 20, no. 6, pp. 13871392, 2008. 
[12] J. F. Chen, P. Xu, S. Y. Zhu, and Y. J. Hu, "Advance in research for pharmacokinetics and drug interactions of licorice," Chinese Journal of Clinical Pharmacology, vol. 15, no. 10, pp. 1174-1182, 2010.

[13] J. P. Yong, "Advances in studies on the synthesis of Glycyrrhizic acid, Glycyrrhetinic acid derivatives and their biological activities," Lishizhen Medicine and Materia Medica Research, vol. 23, no. 6, pp. 1174-1182, 2012.

[14] S. Matsui, H. Matsumoto, Y. Sonoda et al., "Glycyrrhizin and related compounds down-regulate production of inflammatory chemokines IL- 8 and eotaxin 1 in a human lung fibroblast cell line," International Immunopharmacology, vol. 4, no. 13, pp. 1633-1644, 2004.

[15] H.-Y. Park, S.-H. Park, H.-K. Yoon, J. H. Myung, and D.-H. Kim, "Anti-allergic activity of $18 \beta$-glycyrrhetinic acid-3-O- $\beta$ D-glucuronide," Archives of Pharmacal Research, vol. 27, no. 1, pp. 57-60, 2004.

[16] Y. Matsumoto, T. Matsuura, H. Aoyagi et al., "Antiviral activity of Glycyrrhizin against Hepatitis C virus in vitro," PLoS ONE, vol. 8, no. 7, pp. 1-10, 2013.

[17] J.-H. Tu, D.-L. Hu, L.-L. Dai et al., "Effect of glycyrrhizin on CYP2C19 and CYP3A4 activity in healthy volunteers with different CYP2C19 genotypes," Xenobiotica, vol. 40, no. 6, pp. 393-399, 2010.

[18] Y. Nishimoto, A. Hisatsune, H. Katsuki, T. Miyata, K. Yokomizo, and Y. Isohama, "Glycyrrhizin attenuates mucus production by inhibition of MUC5AC mRNA expression in vivo and in vitro," Journal of Pharmacological Sciences, vol. 113, no. 1, pp. 76-83, 2010.

[19] H. Takii, T. Kometani, T. Nishimura, T. Nakae, S. Okada, and T. Fushiki, "Antidiabetic effect of glycyrrhizin in genetically diabetic KK-Ay mice," Biological and Pharmaceutical Bulletin, vol. 24, no. 5, pp. 484-487, 2001.

[20] C.-X. Zeng, Q. Yang, and Q. Hu, "A comparison of the distribution of two glycyrrhizic acid epimers in rat tissues," European Journal of Drug Metabolism and Pharmacokinetics, vol. 31, no. 4, pp. 253-258, 2006.

[21] M. P. Manns, H. Wedemeyer, A. Singer et al., "Glycyrrhizin in patients who failed previous interferon alpha-based therapies: biochemical and histological effects after 52 weeks," Journal of Viral Hepatitis, vol. 19, no. 8, pp. 537-546, 2012.

[22] N. Abe, T. Ebina, and N. Ishida, "Interferon induction by glycyrrhizin and glycyrrhetinic acid in mice," Microbiology and Immunology, vol. 26, no. 6, pp. 535-539, 1982.

[23] S. Yasui, K. Fujiwara, A. Tawada, Y. Fukuda, M. Nakano, and O. Yokosuka, "Efficacy of intravenous glycyrrhizin in the early stage of acute onset autoimmune hepatitis," Digestive Diseases and Sciences, vol. 56, no. 12, pp. 3638-3647, 2011.

[24] Y. Arase, K. Ikeda, N. Murashima et al., "The long term efficacy of Glycyrrhizin in chronic hepatitis C patients," Cancer, vol. 79, no. 8, pp. 1494-1500, 1997.

[25] K. Ikeda, "Glycyrrhizin injection therapy prevents hepatocellular carcinogenesis in patients with interferon-resistant active chronic hepatitis C," Hepatology Research, vol. 37, no. 2, pp. S287-S293, 2007.

[26] H.-F. Wang, H.-B. Su, H.-L. Liu et al., "Clinical research on treatment on several kinds of liver hepatitis with diammonium glycyrrhizinate," Chinese Journal of Infectious Diseases, vol. 22, no. 2, pp. 113-115, 2004.

[27] Y. Cao, X.-Y. Tang, and F.-W. Song, "Compare of and betaGlycyrrhetinic acid alpha-Glycyrrhetinic acid in the treatment of Chronic Hepatitis B," China Journal of Modern Medicine, vol. 12, no. 7, pp. 91-92, 2002.

[28] Q.-T. Xu, "Clinical observation of magnesium isoglycyrrhizinate in the treatment of chronic hepatitis B," Journal of Clinical Hepatology, vol. 23, no. 4, pp. 282-283, 2007.

[29] X.-J. Shen, Z.-L. Liu, and Y.-Z. Xue, "Observation of magnesium isoglycyrrhizinate in the treatment of chronic severe hepatitis," Journal of Clinical Medicine in Practice, vol. 11, no. 6, pp. 71-72, 2007.

[30] H.-C. Ni, Y.-Y. Qi, and W.-D. Feng, "Effect of magnesium isoglycyrrhizinate in the treatment of the hepatotoxicity caused by anti-tumor agents in cancer patients," Anhui Medical and Pharmaceutical Journal, vol. 13, no. 9, pp. 1099-1100, 2009.

[31] T. Genovese, M. Menegazzi, E. Mazzon et al., "Glycyrrhizin reduces secondary inflammatory process after spinal cord compression injury in mice," Shock, vol. 31, no. 4, pp. 367-375, 2009.

[32] A. Lin, Y. Liu, Y. Huang et al., "Glycyrrhizin surface-modified chitosan nanoparticles for hepatocyte-targeted delivery," International Journal of Pharmaceutics, vol. 359, no. 1-2, pp. 247-253, 2008.

[33] M. Korenaga, I. Hidaka, S. Nishina et al., "A glycyrrhizin-containing preparation reduces hepatic steatosis induced by hepatitis C virus protein and iron in mice," Liver International, vol. 31, no. 4, pp. 552-560, 2011.

[34] G.-Q. Zang, X.-Q. Zhou, H. Yu et al., "Effect of hepatocyte apoptosis induced by TNF- $\alpha$ on acute severe hepatitis in mouse models," World Journal of Gastroenterology, vol. 6, no. 5, pp. 688-692, 2000.

[35] M. Rivero, J. Crespo, E. Fábrega et al., "Apoptosis mediated by the Fas system in the fulminant hepatitis by hepatitis B virus," Journal of Viral Hepatitis, vol. 9, no. 2, pp. 107-113, 2002.

[36] C. J. McClain, “Tumor necrosis and alcoholic hepatitis," Hepatology, vol. 14, no. 2, pp. 394-396, 1991.

[37] D. R. Green, "Apoptotic pathways: paper wraps stone blunts scissors," Cell, vol. 102, no. 1, pp. 1-4, 2000.

[38] N. F. El-Tahawy, A. H. Ali, S. R. Saied, and Z. A. Wahab, "Effect of glycyrrhizin on lipopolysaccharide/D-galactosamineinduced acute hepatitis in albino rats: a histological and immunohistochemical study," The Egyptian Journal of Histology, vol. 34, no. 3, pp. 518-527, 2011.

[39] B. Tang, H. Qiao, F. Meng, and X. Sun, "Glycyrrhizin attenuates endotoxin-induced acute liver injury after partial hepatectomy in rats," Brazilian Journal of Medical and Biological Research, vol. 40, no. 12, pp. 1637-1646, 2007.

[40] C.-C. Hu, W.-K. Chen, P.-H. Liao, W.-C. Yu, and Y.-J. Lee, "Synergistic effect of cadmium chloride and acetaldehyde on cytotoxicity and its prevention by quercetin and glycyrrhizin," Mutation Research: Genetic Toxicology and Environmental Mutagenesis, vol. 496, no. 1-2, pp. 117-127, 2001.

[41] C.-L. Zhai, M.-Q. Zhang, Y. Zhang et al., "Glycyrrhizin protects rat heart against ischemia-reperfusion injury through blockade of HMGB1-dependent phospho-JNK/Bax pathway," Acta Pharmacologica Sinica, vol. 33, no. 12, pp. 1477-1487, 2012.

[42] B. Ni, Z. Y. Cao, and Y. Liu, "Glycyrrhizin protects spinal cord and reduces inflammation in spinal cord ischemia-reperfusion injury," International Journal of Neuroscience, vol. 123, no. 11, pp. 745-751, 2013.

[43] M. Ogiku, H. Kono, M. Hara, M. Tsuchiya, and H. Fujii, “Glycyrrhizin prevents liver injury by inhibition of high-mobility 
group box 1 production by kupffer cells after ischemiareperfusion in rats," Journal of Pharmacology and Experimental Therapeutics, vol. 339, no. 1, pp. 93-98, 2011.

[44] S. Rahman and S. Sultana, "Chemopreventive activity of glycyrrhizin on lead acetate mediated hepatic oxidative stress and its hyperproliferative activity in Wistar rats," Chemico-Biological Interactions, vol. 160, no. 1, pp. 61-69, 2006.

[45] C.-T. Tu, J. Li, F.-P. Wang, L. Li, J.-Y. Wang, and W. Jiang, "Glycyrrhizin regulates $\mathrm{CD} 4{ }^{+} \mathrm{T}$ cell response during liver fibrogenesis via JNK, ERK and PI3K/AKT pathway," International Immunopharmacology, vol. 14, no. 4, pp. 410-421, 2012.

[46] H. Honda, Y. Nagai, T. Matsunaga et al., "Glycyrrhizin and isoliquiritigenin suppress the LPS sensor Toll-like receptor 4/MD-2 complex signaling in a different manner," Journal of Leukocyte Biology, vol. 91, no. 6, pp. 967-976, 2012.

[47] B. Schröfelbauer, J. Raffetseder, M. Hauner, A. Wolkerstorfer, W. Ernst, and O. H. J. Szolar, "Glycyrrhizin, the main active compound in liquorice, attenuates pro-inflammatory responses by interfering with membrane-dependent receptor signalling," Biochemical Journal, vol. 421, pp. 473-482, 2009.

[48] Y. Fujisawa, M. Sakamoto, M. Matsushita, T. Fujita, and K. Nishioka, "Glycyrrhizin inhibits the lytic pathway of complement: possible mechanism of its anti-inflammatory effect on liver cells in viral hepatitis," Microbiology and Immunology, vol. 44, no. 9, pp. 799-804, 2000.

[49] M. Takei, M. Kobayashi, D. N. Herndon, R. B. Pollard, and F. Suzuki, "Glycyrrhizin inhibits the manifestations of antiinflammatory responses that appear in association with systemic inflammatory response syndrome (SIRS)-like reactions," Cytokine, vol. 35, no. 5-6, pp. 295-301, 2006.

[50] M. Menegazzi, R. Di Paola, E. Mazzon et al., "Glycyrrhizin attenuates the development of carrageenan-induced lung injury in mice," Pharmacological Research, vol. 58, no. 1, pp. 22-31, 2008.

[51] J. Cinatl, B. Morgenstern, G. Bauer, P. Chandra, H. Rabenau, and H. W. Doerr, "Glycyrrhizin, an active component of liquorice roots, and replication of SARS-associated coronavirus," The Lancet, vol. 361, no. 9374, pp. 2045-2046, 2003.

[52] U. A. Ashfaq, M. S. Masoud, Z. Nawaz, and S. Riazuddin, "Glycyrrhizin as antiviral agent against Hepatitis C Virus," Journal of Translational Medicine, vol. 9, no. 1, article 112, 2011.

[53] R. Xu, X. Zhang, and J. Yang, "Effects of glycyrrhizin on biliary transport and hepatic levels of glutathione in rats," Biopharmaceutics and Drug Disposition, vol. 33, no. 5, pp. 235-245, 2012.

[54] J. König, A. T. Nies, Y. Cui, I. Leier, and D. Keppler, "Conjugate export pumps of the multidrug resistance protein (MRP) family: localization, substrate specificity, and MRP2-mediated drug resistance," Biochimica et Biophysica Acta: Biomembranes, vol. 1461, no. 2, pp. 377-394, 1999.

[55] X.-J. Liang and A. Aszalos, "Multidrug transporters as drug targets," Current Drug Targets, vol. 7, no. 8, pp. 911-921, 2006.

[56] M. Masuda, Y. I'izuka, M. Yamazaki et al., "Methotrexate is excreted into the bile by canalicular multispecific organic anion transporter in rats," Cancer Research, vol. 57, no. 16, pp. 35063510, 1997.

[57] A. Morikawa, Y. Goto, H. Suzuki, T. Hirohashi, and Y. Sugiyama, "Biliary excretion of $17 \beta$-estradiol $17 \beta$-D-glucuronide is predominantly mediated by cMOAT/MRP2," Pharmaceutical Research, vol. 17, no. 5, pp. 546-552, 2000.
[58] H. Sun, Y.-Y. Zeng, and K.-S. Pang, "Interplay of phase II enzymes and transporters in futile cycling: influence of multidrug resistance-associated protein 2-mediated excretion of estradiol $17 \beta$-D-glucuronide and its 3-sulfate metabolite on net sulfation in perfused TR- and wistar rat liver preparations," Drug Metabolism and Disposition, vol. 38, no. 5, pp. 769-780, 2010.

[59] J.-H. Dai, Y. Iwatani, T. Ishida et al., "Glycyrrhizin enhances interleukin-12 production in peritoneal macrophages," Immunology, vol. 103, no. 2, pp. 235-243, 2001.

[60] K. Mori, H. Sakai, S. Suzuki et al., "Effects of glycyrrhizin (SNMC: stronger neo-minophagen C) in hemophilia patients with HIV-1 infection," Tohoku Journal of Experimental Medicine, vol. 162, no. 2, pp. 183-193, 1990.

[61] C. Miyaji, R. Miyakawa, H. Watanabe, H. Kawamura, and T. Abo, "Mechanisms underlying the activation of cytotoxic function mediated by hepatic lymphocytes following the administration of glycyrrhizin," International Immunopharmacology, vol. 2, no. 8, pp. 1079-1086, 2002.

[62] H. Sato, S. Kageyama, H. Yamamoto et al., "Glycyrrhizin renders cells resistant to apoptosis induced by human and feline immunodeficiency virus," Journal of Traditional Medicines, vol. 28, no. 3, pp. 139-148, 2011.

[63] K. Ohuchi, Y. Kamada, L. Levine, and S. Tsurufuji, "Glycyrrhizin inhibits prostaglandin E2 production by activated peritoneal macrophages from rats," Prostaglandins and Medicine, vol. 7, no. 5, pp. 457-463, 1981.

[64] R. Pompei, O. Flore, and M. A. Marccialis, "Glycyrrhizic acid inhibits virus growth and inactivates virus particles," Nature, vol. 281, no. 5733, pp. 689-690, 1979.

[65] H. Y. Park, S. H. Park, H. K. Yoon, M. J. Han, and D. H. Kim, "Anti-allergic activity of 18 beta-glycyrrhetinic acid-3-O-betaD-glucuronide," Archives of Pharmacal Research, vol. 27, no. 1, pp. 57-60, 2004.

[66] S. Tanaka, C. Uno, M. Akimoto, M. Tabata, C. Honda, and W. Kamisako, "Anti-allergic effect of bryonolic acid from Luffa cylindrica cell suspension cultures," Planta Medica, vol. 57, no. 6, pp. 527-530, 1991.

[67] Z. Kawakami, Y. Ikarashi, and Y. Kase, "Glycyrrhizin and its metabolite $18 \beta$-glycyrrhetinic acid in glycyrrhiza, a constituent herb of yokukansan, ameliorate thiamine deficiency-induced dysfunction of glutamate transport in cultured rat cortical astrocytes," European Journal of Pharmacology, vol. 626, no. 2-3, pp. 154-158, 2010.

[68] X. Zhu, C. Chen, D. Ye et al., "Diammonium glycyrrhizinate upregulates PGC- $1 \alpha$ and protects against A $\beta 1-42$-induced neurotoxicity," PLoS ONE, vol. 7, no. 4, Article ID e35823, 2012.

[69] J.-Y. Shim, S.-B. Yim, J.-H. Chung, and K.-S. Hong, "Antiplaque and antigingivitis effects of a mouthrinse containing cetylpyridinium chloride, triclosan and dipotassium glycyrrhizinate," Journal of Periodontal and Implant Science, vol. 42, no. 2, pp. 33-38, 2012.

[70] H.-X. Gao, S.-H. Shao, and G.-Q. Wang, "Research progress of Radix Glycyrrhizae," Journal of Jinggangshan Medical College, vol. 11, no. 5, pp. 8-11, 2004.

[71] X.-L. Li and A.-G. Zhou, "Evaluation of the immunity activity of glycyrrhizin in AR mice," Molecules, vol. 17, no. 1, pp. 716-727, 2012.

[72] V. P. Makarenkova, V. Bansal, B. M. Matta, L. A. Perez, and J. B. Ochoa, "CD11b" $/ \mathrm{Gr}-1^{+}$myeloid suppressor cells cause $\mathrm{T}$ cell dysfunction after traumatic stress," Journal of Immunology, vol. 176, no. 4, pp. 2085-2094, 2006. 
[73] L. Steinstraesser, C. Schubert, F. Jacobsen, and S. Al-Benna, "Glycyrrhizin against multi-resistant bacteria?" Journal of Leukocyte Biology, vol. 87, no. 1, pp. 7-8, 2010.

[74] T. Utsunomiya, M. Kobayashi, M. Ito, D. N. Herndon, R. B. Pollard, and F. Suzuki, "Glycyrrhizin restores the impaired IL-12 production in thermally injured mice," Cytokine, vol. 14, no. 1, pp. 49-55, 2001.

[75] Y.-H. Zhang, K. Isobe, F. Nagase et al., "Glycyrrhizin as a promoter of the late signal transduction for interleukin-2 production by splenic lymphocytes," Immunology, vol. 79, no. 4, pp. 528-534, 1993.

[76] X.-L. Li, A.-G. Zhou, L. Zhang, and W.-J. Chen, "Antioxidant status and immune activity of glycyrrhizin in allergic rhinitis mice," International Journal of Molecular Sciences, vol. 12, no. 2, pp. 905-916, 2011.

[77] M. Michaelis, J. Geiler, P. Naczk et al., "Glycyrrhizin exerts antioxidative effects in $\mathrm{H} 5 \mathrm{~N} 1$ influenza A virus-infected cells and inhibits virus replication and pro-inflammatory gene expression," PLoS ONE, vol. 6, no. 5, Article ID e19705, 2011.

[78] M. Paolini, J. Barillari, M. Broccoli, L. Pozzetti, P. Perocco, and G. Cantelli-Forti, "Effect of liquorice and glycyrrhizin on rat liver carcinogen metabolizing enzymes," Cancer Letters, vol. 145, no. 1-2, pp. 35-42, 1999.

[79] H.-T. Chan, C. Chan, and J.-W. Ho, "Inhibition of glycyrrhizic acid on aflatoxin B1-induced cytotoxicity in hepatoma cells," Toxicology, vol. 188, no. 2-3, pp. 211-217, 2003.

[80] L.-L. Shi, C. Tang, and C.-H. Yin, "Glycyrrhizin-modified Ocarboxymethyl chitosan nanoparticles as drug vehicles targeting hepatocellular carcinoma," Biomaterials, vol. 33, no. 30, pp. 7594-7604, 2012.

[81] G. Shiota, K.-I. Harada, M. Ishida et al., "Inhibition of hepatocellular carcinoma by glycyrrhizin in diethylnitrosaminetreated mice," Carcinogenesis, vol. 20, no. 1, pp. 59-63, 1999.

[82] J.-H. Tu, Y.-J. He, Y. Chen et al., "Effect of glycyrrhizin on the activity of CYP3A enzyme in humans," European Journal of Clinical Pharmacology, vol. 66, no. 8, pp. 805-810, 2010.

[83] B. A. Carneiro-Filho, I. P. F. Lima, D. H. Araujo et al., "Intestinal barrier function and secretion in methotrexate-induced rat intestinal mucositis," Digestive Diseases and Sciences, vol. 49, no. 1, pp. 65-72, 2004.

[84] S.-P. Lin, S.-Y. Tsai, Y.-C. Hou, and P.-D. L. Chao, "Glycyrrhizin and licorice significantly affect the pharmacokinetics of methotrexate in rats," Journal of Agricultural and Food Chemistry, vol. 57, no. 5, pp. 1854-1859, 2009.

[85] W. E. Evans, W. R. Crom, and M. Abromowitch, "Clinical pharmacodynamics of high-dose methotrexate in acute lymphocytic leukemia. Identification of a relation between concentration and effect," The New England Journal of Medicine, vol. 314, no. 8, pp. 471-476, 1986.

[86] M. Tishler, D. Caspi, and M. Yaron, "Long-term experience with low dose methotrexate in rheumatoid arthritis," Rheumatology International, vol. 13, no. 3, pp. 103-106, 1993.

[87] J. Chladek, J. Grim, J. Martinkova, M. Simkova, and J. Vaneckova, "Low-dose methotrexate pharmacokinetics and pharmacodynamics in the therapy of severe psoriasis," Basic and Clinical Pharmacology and Toxicology, vol. 96, no. 3, pp. 247248, 2005.

[88] A. L. A. Kuijpers and P. C. M. van de Kerkhof, "Risk-benefit assessment of methotrexate in the treatment of severe psoriasis," The American Journal of Clinical Dermatology, vol. 1, no. 1, pp. 27-39, 2000.
[89] Y. Maeda, N. Inaba, M. Aoyagi, T. Tanase, and T. Shiigai, "Pseudoaldosteronism caused by combined administration of cilostazol and glycyrrhizin," Internal Medicine, vol. 47, no. 14, pp. 13451348, 2008.

[90] T. Zenone and Q. Blanc, "Rhabdomyolysis with major hypokalemia secondary to chronic glycyrrhizic acid ingestion," Revue de Medecine Interne, vol. 30, no. 1, pp. 78-80, 2009.

[91] R. K. Støving, L. E. Lingqvist, R. K. Bonde et al., "Is glycyrrhizin sensitivity increased in anorexia nervosa and should licorice be avoided? Case report and review of the literature," Nutrition, vol. 27, no. 7-8, pp. 855-858, 2011.

[92] S. Sen, M. Roy, and A. S. Chakraborti, "Ameliorative effects of glycyrrhizin on streptozotocin-induced diabetes in rats," Journal of Pharmacy and Pharmacology, vol. 63, no. 2, pp. 287296, 2011.

[93] D.-G. Kang, E.-J. Sohn, and H.-S. Lee, "Effects of glycyrrhizin on renal functions in association with the regulation of water channels," The American Journal of Chinese Medicine, vol. 31, no. 3, pp. 403-413, 2003.

[94] D.-G. Kang, E.-J. Sohn, Y.-J. Mun, W.-H. Woo, and H.-S. Lee, "Glycyrrhizin ameliorates renal function defects in the earlyphase of ischemia-induced acute renal failure," Phytotherapy Research, vol. 17, no. 8, pp. 947-951, 2003.

[95] Y. Lee, S. Jeong, W. Kim et al., "Glycyrrhizin enhances therapeutic activity of a colon-specific methylprednisolone prodrug against experimental colitis," Digestive Diseases and Sciences, vol. 58, no. 5, pp. 1226-1234, 2013.

[96] T. Rossi, L. Benassi, C. Magnoni, A. I. Ruberto, A. Coppi, and G. Baggio, "Effects of glycyrrhizin on UVB-irradiated melanoma cells," In Vivo, vol. 19, no. 1, pp. 319-322, 2005.

[97] A. B. Hocaoglu, O. Karaman, D. O. Erge et al., "Glycyrrhizin and long-term histopathologic changes in a murine model of asthma," Current Therapeutic Research: Clinical and Experimental, vol. 72, no. 6, pp. 250-261, 2011.

[98] A. Ram, U. Mabalirajan, M. Das et al., "Glycyrrhizin alleviates experimental allergic asthma in mice," International Immunopharmacology, vol. 6, no. 9, pp. 1468-1477, 2006.

[99] Y.-F. Ni, J.-K. Kuai, Z.-F. Lu et al., "Glycyrrhizin treatment is associated with attenuation of lipopolysaccharide-induced acute lung injury by inhibiting cyclooxygenase- 2 and inducible nitric oxide synthase expression," Journal of Surgical Research, vol. 165, no. 1, pp. e29-e35, 2011.

[100] M. L. Parisella, T. Angelone, A. Gattuso, M. C. Cerra, and D. Pellegrino, "Glycyrrhizin and glycyrrhetinic acid directly modulate rat cardiac performance," Journal of Nutritional Biochemistry, vol. 23, no. 1, pp. 69-75, 2012.

[101] Y. J. Kim and C. S. Lee, "Glycyrrhizin attenuates MPTP neurotoxicity in mouse and $\mathrm{MPP}^{+}$-induced cell death in $\mathrm{PC1} 2$ cells," Korean Journal of Physiology and Pharmacology, vol. 12, no. 2, pp. 65-71, 2008.

[102] J. H. Song, J. W. Lee, B. Shim, and C. Y. Lee, "Glycyrrhizin alleviates neuroinflammation and memory deficit Induced by systemic lipopolysaccharide treatment in mice," Molecules, vol. 18, no. 12, pp. 15788-15803, 2013.

[103] Z. Song, Y. Gong, H. Liu, Q. Ren, and X. Sun, "Glycyrrhizin could reduce ocular hypertension induced by triamcinolone acetonide in rabbits," Molecular Vision, vol. 17, pp. 2056-2064, 2011.

[104] T. Utsunomiya, M. Kobayashi, M. Ito, R. B. Pollard, and F. Suzuki, "Glycyrrhizin improves the resistance of MAIDS mice to opportunistic infection of Candida albicans through the 
modulation of MAIDS-associated type 2 T cell responses," Clinical Immunology, vol. 95, no. 2, pp. 145-155, 2000.

[105] T. Yoshida, Y. Tsuda, D. Takeuchi, M. Kobayashi, R. B. Pollard, and F. Suzuki, "Glycyrrhizin inhibits neutrophil-associated generation of alternatively activated macrophages," Cytokine, vol. 33, no. 6, pp. 317-322, 2006.

[106] Y.-M. Mao, M.-D. Zeng, Y. Chen et al., "Magnesium isoglycyrrhizinate in the treatment of chronic liver diseases: a randomized, double-blind, multi-doses, active drug controlled, multicenter study," Zhonghua Gan Zang Bing Za Zhi, vol. 17, no. 11, pp. 847-851, 2009.

[107] Z.-W. Xiao, W. Zhang, L. Ma, and Z.-W. Qiu, “Therapeutic effect of magnesium isoglycyrrhizinate in rats on lung injury induced by paraquat poisoning," European Review for Medical and Pharmacological Sciences, vol. 18, no. 3, pp. 311-320, 2014.

[108] J. Zhao, X.-Y. Wan, M. Luo, T.-S. Chen, and P. He, "Antifibrotic effects of glycyrrhizin and matrine in vitro and in vivo," Biomedicine and Preventive Nutrition, vol. 2, no. 2, pp. 132-137, 2012.

[109] X.-Y. Wan, M. Luo, X.-D. Li, and P. He, "Hepatoprotective and anti-hepatocarcinogenic effects of glycyrrhizin and matrine," Chemico-Biological Interactions, vol. 181, no. 1, pp. 15-19, 2009.

[110] C.-A. Ren, Y.-X. Li, and J.-Y. Cui, "Efficacy of glycyrrhizin combined with cyclosporine in the treatment of non-severe aplastic anemia," Chinese Medical Journal, vol. 126, no. 11, pp. 2083-2086, 2013.

[111] Y.-Q. Meng, J.-Q. Ding, Y. Liu, H.-H. Nie, S. Guan et al., "Synthesis and anti-tumor activity of novel glycyrrhetinic acid derivatives," Chemical Research in Chinese Universities, vol. 28, no. 2, pp. 214-219, 2012.

[112] Y. Mizushina, T. Ishida, S. Yagi et al., "Inhibitory effects of glycyrrhetinic acid on DNA polymerase and inflammatory activities," Evidence-Based Complementary and Alternative Medicine, vol. 2012, Article ID 650514, 9 pages, 2012.

[113] R. Mencucci, E. Favuzza, and U. Menchini, "Assessment of the tolerability profile of an ophthalmic solution of 5\% glycyrrhizin and copolymer PEG PPG on healthy volunteers and evaluation of its efficacy in the treatment of moderate to severe blepharitis," Clinical Ophthalmology, vol. 7, pp. 1403-1410, 2013.

[114] M. E. Hardy, J. M. Hendricks, J. M. Paulson, and N. R. Faunce, "18 $\beta$-glycyrrhetinic acid inhibits rotavirus replication in culture," Virology Journal, vol. 9, no. 96, pp. 1-7, 2012. 

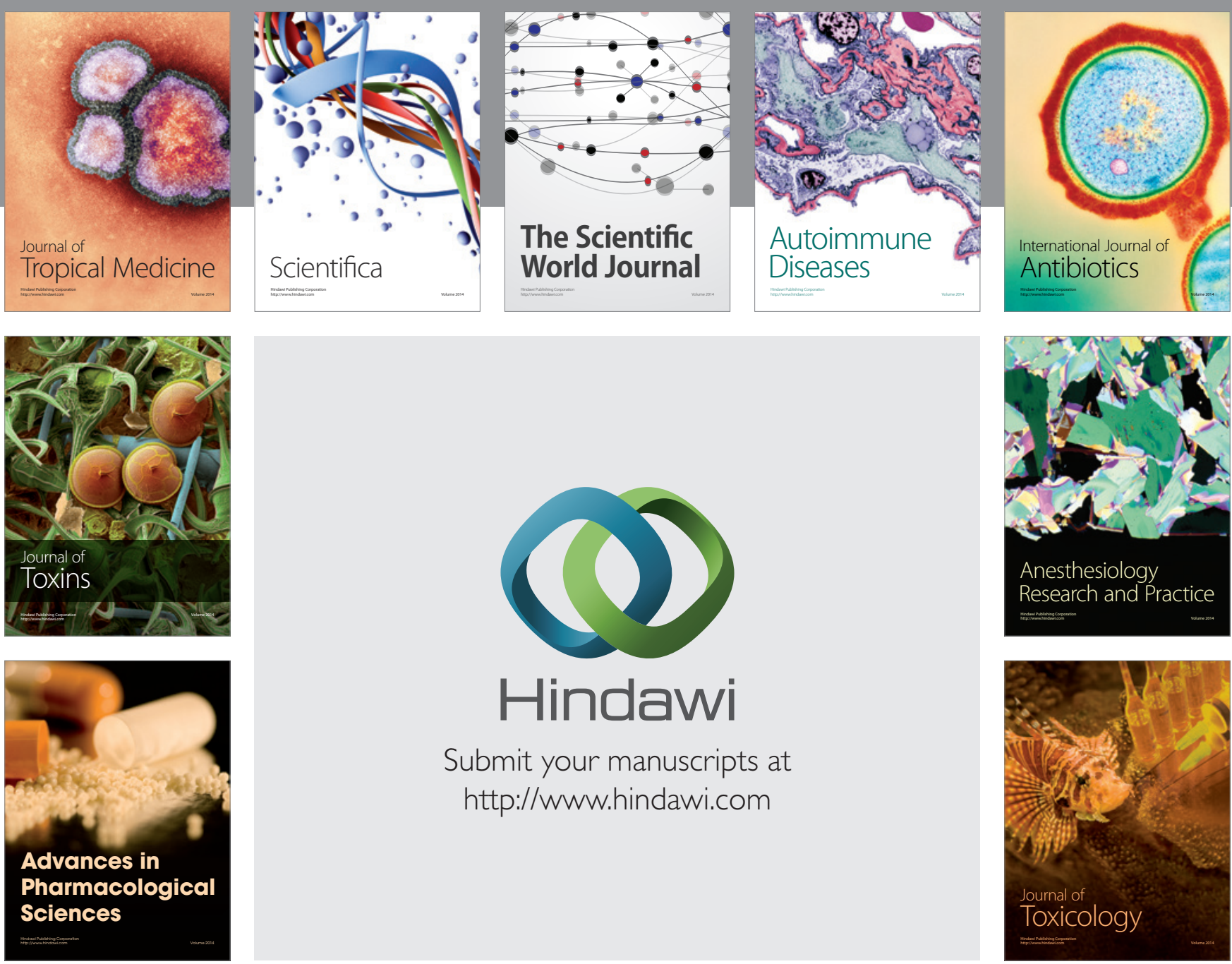

\section{Hindawi}

Submit your manuscripts at

http://www.hindawi.com
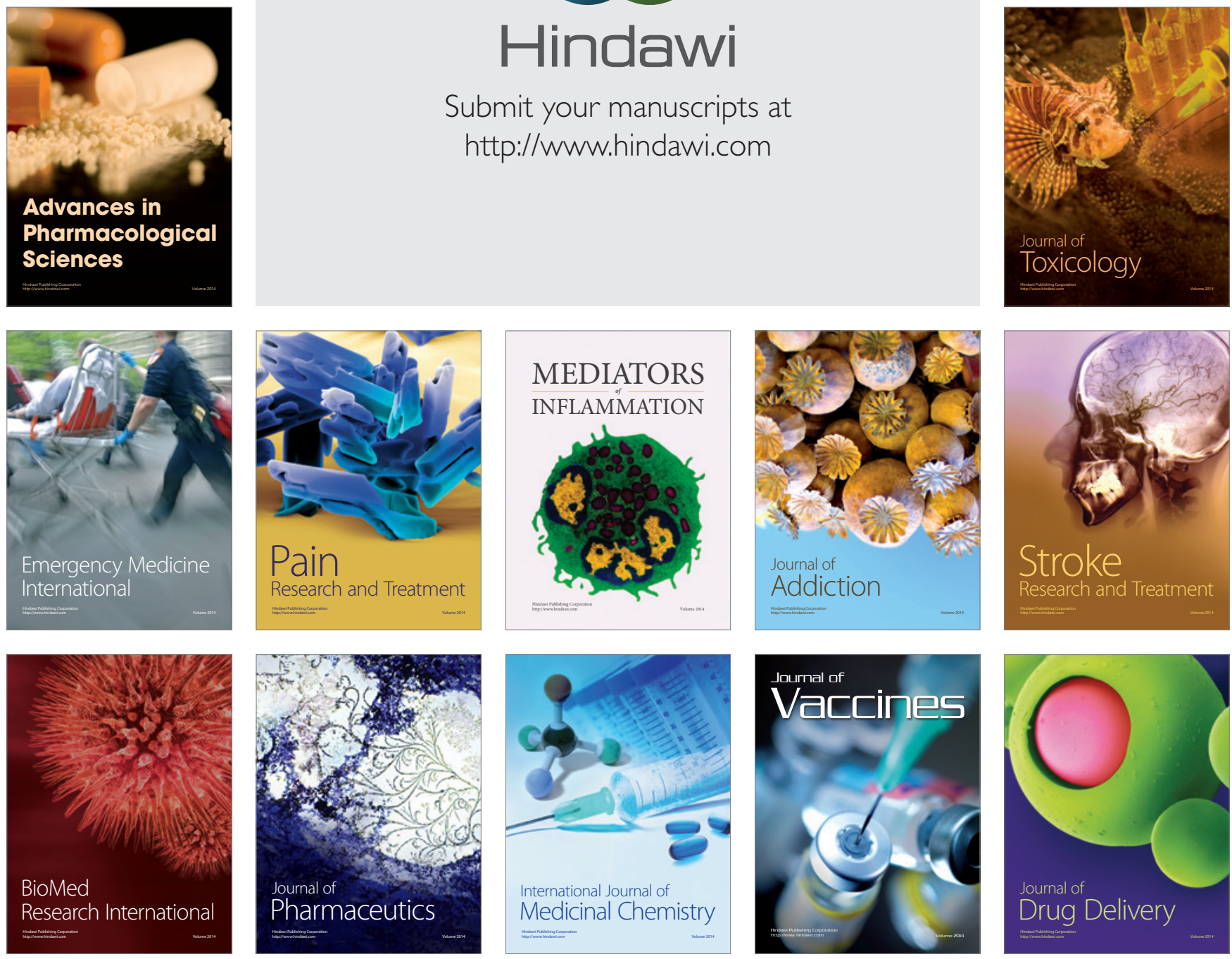